\title{
Vascular Endothelial Growth Factor Mediates the Sprouted Axonogenesis of Breast Cancer in Rat
}

\author{
Hongxiu Han, ${ }^{\star \dagger}$ Chunxue Yang ${ }^{\dagger}$ Yuan Zhang, ${ }^{\dagger}$ Changhao Han,${ }^{\ddagger}$ and Guohua Zhang
}

\begin{abstract}
From the Department of Pathology, * Tongji Hospital, Tongji University, Shanghai; the Department of Pathology, ${ }^{\dagger}$ Shanghai Ninth People's Hospital, and the Department of Anatomy and Physiology, ${ }^{\S}$ Shanghai Jiao Tong University School of Medicine, Shanghai; and the Department of Clinical Medicine, ${ }^{\ddagger}$ Second Clinical Medical College, Chongqing Medical University, Chongqing, China
\end{abstract}

\author{
Accepted for publication \\ December 7, 2020. \\ Address correspondence to \\ Guohua Zhang, M.D., Ph.D., \\ Department of Anatomy and \\ Physiology, Shanghai Jiao \\ Tong University School of \\ Medicine, 280 S. Chongqing \\ Rd., Shanghai 200025, China; \\ or Hongxiu Han, M.D., Ph.D., \\ Department of Pathology, \\ Tongji Hospital, Tongji \\ University, 389 Xincun \\ Rd., Shanghai 200065, \\ China. E-mail: hxhan2004@ \\ hotmail.com or ghzhang2009@ \\ shsmu.edu.cn.
}

\begin{abstract}
Nerve infiltration into the tumor is a common feature of the tumor microenvironment. The mechanisms of axonogenesis in breast cancer remain unclear. We hypothesized that vascular endothelial growth factor (VEGF), as well as nerve growth factor (NGF), is involved in the axonogenesis of breast cancer. A $\mathrm{N}$-methyl- $\mathrm{N}$-nitrosourea (MNU)-induced rat model of breast cancer was used to explore the presence of axonogenesis in breast tumor and the involvement of VEGF, as well as NGF, in the axonogenesis of breast tumor. Nerve infiltration into the tumor was found in $\mathrm{MNU}$-induced rat model of breast cancer including the sensory and sympathetic nerve fibers. Nerve density was increased following the growth of tumor. The sensory neurons innervating the thoracic and abdominal mammary tumors peaked at T5 to T6 and L1 to L2 dorsal root ganglions, respectively. Either VEGF receptor inhibitor or antibody against VEGF receptor 2, as well as NGF receptor inhibitor, apparently decreased both the nerve density and vascular density of breast tumor. The reduced nerve density was correlated with the decreased vascular density induced by these treatments. In cultured dorsal root ganglion neurons, phosphatidylinositol 3 (PI3K)/Akt, extracellular signal-regulated protein kinase (ERK), and p38 inhibitors significantly attenuated VEGF-induced neurite elongation. These findings provide direct evidence that VEGF, as well as NGF, may control the axonogenesis of breast cancer. (Am J Pathol 2021, 191: 515-526; https:// doi.org/10.1016/j.ajpath.2020.12.006)
\end{abstract}

The tumor microenvironment, consisting of fibroblasts, immune and inflammatory cells, blood, lymphatic vessels, and nerves, has various influences on tumor development and patients' survival. There has been an increasing interest in the biological phenomenon of active axonogenesis that occurs in tumor, and provides insight into therapeutic implications of neural regulation of tumor progression.

Accumulating evidence suggests that axonogenesis occurs in cancer located in human prostate, ${ }^{1,2}$ colon, ${ }^{3}$ breast, ${ }^{4}$ and pancreas, ${ }^{5,6}$ which indicates axonogenesis is viewed as a risk factor for poor prognosis of cancer. For example, Albo et $\mathrm{al}^{3}$ demonstrated that axonogenesis of tumor plays a key role in colorectal cancer progression. The authors' previous study demonstrated that nerve density was associated with tumor grade, angiogenesis, and patient survival. ${ }^{4}$ Olar et $\mathrm{al}^{2}$ reported that nerve density had a positive correlation with lymph node status. In addition, some studies provide direct evidence that infiltration of tumors by growing nerves contributes to cancer progression. Magnon et $\mathrm{al}^{7}$ demonstrated that sympathetic nerves are involved in the early phase of tumor development, whereas parasympathetic nerves are responsible for the cancer dissemination. Zhao et $\mathrm{al}^{8}$ have shown that denervation of the stomach significantly attenuates tumor incidence and progression.

Axonogenesis impacts cancer progression; thus, it must be asked what drives axonogenesis in cancer. Although the

Supported by National Natural Science Foundation of China grants 81770533, 81070891 (G.Z.), and 81272927 (H.H.).

H.H., C.Y., and Y.Z. equally contributed to this work.

Disclosures: None declared. 
latest studies indicate that neural progenitors leave the subventricular zone, reach the primary tumor through the blood, and differentiate into new neurons, much attention has been paid to the fact that the neurotropic growth factors such as nerve growth factor (NGF) and granulocyte colonystimulating factor in the tumor microenvironment promote the axon sprout from pre-existing nerves into the tumors. $^{9-12}$ One study demonstrated that NGF production is associated with the infiltration of nerve fibers in breast cancer. ${ }^{13}$ Intriguingly, vascular endothelial growth factor (VEGF) plays important roles in neurogenesis as well as angiogenesis. ${ }^{14-16}$ The authors' previous study indicated that axonogenesis is correlated with angiogenesis in human breast cancer. ${ }^{4}$ There is documented evidence showing that VEGF activates numerous cellular transduction signals such as phosphatidylinositol 3 (PI3K)/Akt and mitogen-activated protein kinases (MAPKs) in neuron functions. ${ }^{17,18}$ Here, the contribution of VEGF, as well as NGF, to the axonogenesis of breast cancer was investigated using a rat model established by the carcinogen $N$-methyl- $N$-nitrosourea (MNU).

\section{Materials and Methods}

\section{Animals}

Female Sprague-Dawley rats aged 7 weeks $(n=150)$ and 14 days $(n=27)$ were purchased from Shanghai Jiao Tong University School of Medicine Animal Center and used for in vivo and in vitro studies, respectively. Animals were housed at $24^{\circ} \mathrm{C}$ with a $12: 12$-hour light/dark cycle. Standard rat chow and water were provided ad libitum. All of the experimental protocols were approved by the Animal Care and Use Committee of Shanghai Jiao Tong University School of Medicine.

\section{Animal Model}

The most common experimental model of breast cancer in female rats is the induction of DNA alkylation by the carcinogenic agent MNU. ${ }^{19}$ In the current study, breast cancer was established by i.p. injections of $50 \mathrm{mg} / \mathrm{kg}$ MNU (Sigma-Aldrich, St. Louis, MO) dissolved in $0.9 \%$ saline in female Sprague Dawley rats twice (every other month). Tumors were monitored by manual palpation at weekly intervals after the second injection. The rats $(61 / 150,40.6 \%)$ with tumor initially induced between 3 and 4 months after the first injection of MNU were utilized in the current study.

\section{Histologic Assessment}

Breast cancer was histologically determined using hematoxylin and eosin staining. The paraffin-embedded breast tumor tissues were sectioned at 3 to $5 \mu \mathrm{m}$. The sections were stained using hematoxylin solution and counterstained in eosin solution.
For immunohistochemical detection of pan-neuronal marker protein gene product 9.5 (PGP9.5) and blood vessel marker CD34, 3- $\mu \mathrm{m}$ tumor tissue sections were stained with rabbit anti-PGP9.5 antibody (1:200, ab27053; Abcam, Cambridge, MA) or rabbit anti-CD34 antibody (1:500, ab185732; Abcam). The sections were then incubated with goat anti-rabbit antibody followed by $3,3^{\prime}$-diaminobenzidine chromogen (DAB; Dako, Carpinteria, CA). All sections were counterstained with hematoxylin.

Digital images were captured with the Olympus BLISS HD virtual microscopy system (Olympus Corp., Tokyo, Japan) at $\times 400$ magnification. Nerve density was determined by aggregating the pixel density of $\mathrm{PGP} .5^{+}$nerve bundles in 10 representative fields $\left(0.6 \mathrm{~mm}^{2} /\right.$ field $)$ from three to five sections of each animal using ImageJ software version 1.50i, Java 1.6.0 (NIH, Bethesda, MD; http:// imagej.nih.gov/ij) and then converted to the positive nerve area $\left(\mu \mathrm{m}^{2}\right)$. Vascular density was assessed by counting the number of $\mathrm{CD}_{3} 4^{+}$blood vessels in 20 randomly selected fields from two to three sections of each animal.

\section{Immunofluorescence}

To investigate the kinds of afferent and efferent nerve fibers sprouting in breast tumors, the expression of specific sensory nerve marker calcitonin gene-related peptide (CGRP), sympathetic nerve marker vesicular monoamine transporter 2 (VMAT2), and parasympathetic nerve marker vesicular acetylcholine transporter (VAChT), in addition to PGP9.5, was detected by immunofluorescence. Eight rats with breast cancer were transcardially perfused with saline and then with $4 \%$ paraformaldehyde on month 2 after induction of breast tumors.

Fifteen micron sections were incubated with the following antibodies including rabbit anti-PGP9.5 antibody $(1: 1000 ;$ Abcam), rabbit anti-CGRP antibody (1:500, ab47027; Abcam), rabbit anti-VMAT2 antibody (1:500, ab81855; Abcam), or rabbit anti-VAChT antibody (1:200, ab235201; Abcam) and then incubated with secondary goat anti-rabbit antibody conjugated with Alexa Fluor 488 (Thermo Fisher Scientific, Waltham, MA). Staining obtained without primary or secondary antibody was used as a negative control.

\section{Multiplex Immunofluorescence}

To investigate the spatial distribution of sprouted nerves in the breast tumors, multiplex immunofluorescence was used to identify nerve, blood vessel, and tumor epithelium with rabbit anti-PGP9.5 antibody (1:1000; Abcam), rabbit antiCD34 antibody (1:500; Abcam), and mouse anti-cytokeratin (1:500, 4545; Cell Signaling Technology, Beverly, MA) on a single $3-\mu \mathrm{m}$ formalin-fixed, paraffin-embedded tissue section, respectively. To confirm the accuracy of the PGP9.5 antibody in detecting nerve densities in the breast tumor, another mouse anti-neurofilament (NF) antibody (1:500, 
7794; Abcam) was used to determine the colocalization with PGP9.5. Primary antibody was visualized by using tyramide signal amplification linked to a specific fluorochrome including fluorescein isothiocyanate, Cy3, or Cy5 for each primary antibody. A stripping procedure with microwave heating was performed between uniflex immunofluorescence staining. The images were captured using fluorescence confocal microscopy (Leica TCS SP8 STED $3 \times$; Leica Microsystems, Wetzlar, Germany) with the appropriate filter set.

\section{Western Blot Analysis}

On months 1, 2, and 3 after induction of breast tumor, the tumor tissues were harvested from six rats for each stage and homogenized with lysis buffer $[20 \mathrm{mmol} / \mathrm{L}$ Tris- $\mathrm{HCl}$ (pH 8.0), $150 \mathrm{mmol} / \mathrm{L} \mathrm{NaCl}, 1 \mathrm{mmol} / \mathrm{L}$ EDTA, $1 \% \mathrm{NP}-$ $40,1 \mathrm{mmol} / \mathrm{L}$ PMSF] containing protease inhibitor cocktail and phosphatase inhibitor (all from Sigma-Aldrich).

Thirty micrograms of proteins were separated on $4 \%$ to 20\% Tris-glycine ready gels (Bio-Rad Laboratories, Hercules, CA), and then transferred to nitrocellulose membranes (Bio-Rad Laboratories). Blots were incubated with rabbit antibody against PGP9.5 (1:500; Abcam) followed by horseradish peroxidase-conjugated secondary antibody (1:1000; Bio-Rad Laboratories).

\section{Enzyme-Linked Immunosorbent Assay Analysis}

The VEGF and NGF levels in breast tumors from six rats for each stage were measured using rat VEGF enzyme-linked immunosorbent assay kit (ELR-VEGF-001; RayBiotech, Peachtree Corners, GA) and rat beta-NGF enzyme-linked immunosorbent assay kit (ELR-BNGF-001; RayBiotech), respectively, according to the user's manuals. The levels of VEGF and NGF were normalized to the total protein level.

\section{Retrograde Tracing of DiI and Tissue Fixation and Processing}

Rats at month 2 or 3 after induction of tumor were anesthetized with $2 \%$ to $4 \%$ isoflurane in oxygen. A skin incision was made, and $10 \mu \mathrm{L}$ of $0.5 \% 1,1^{\prime}$-diocadecyl-3,3,3',3'tetramethylindocarbocyanine perchlorate (DiI) (D384; Thermo Fisher Scientific), a fluorescent neural tracer, was injected into the tumor. DiI was applied using a 25-ga needle into 10 closely spaced sites. The animals were monitored for 5 to 7 days to recover.

Breast tumors, T3 to T10 and T12 to S1 DRGs, were collected from rats with tumor grown in thoracic and abdominal mammary glands, respectively. Every sixth section was mounted on one slide to avoid repeat counting of cells. Ten sections were counted for each ganglion. DiIlabeled DRG neurons and nerve fibers of breast tumors were observed under fluorescence microscope (Leica DM2500) and images were captured using Leica application suite version 4.3 software (Leica Microsystems).

Treatments with VEGFR Inhibitor, Anti-VEGFR Antibody, and NGFR Inhibitor

To investigate the involvement of VEGF as well as NGF in axonogenesis of breast cancer, 24 rats with breast tumors were randomly assigned to be treated with either VEGF receptor (VEGFR; Flk-1) inhibitor SU5416 (1 mg/ kg, 3037; Tocris, Ellisville, MO), NGF receptor (NGFR; TrkA) inhibitor AG879 (1 mg/kg, 2617; Tocris), antiVEGFR2 antibody (5 $\mu \mathrm{g} / \mathrm{kg}$, ab10972; Abcam), or vehicle (10\% dimethyl sulfoxide) after at least one tumor in the animal reached a diameter $>1 \mathrm{~cm}$. SU5416/AG879 and anti-VEGFR2 antibody were intraperitoneally given every other day and twice a week for 1 month, respectively. The doses used were based on the authors' pilot experiments. Breast tumors were harvested on day 1 after the last treatment. Subsequently, they were frozen and embedded in paraffin to examine the expression of PGP9.5 by Western blot (WB) and immunohistochemistry, respectively.

\section{Preparation of DRG Neurons and Treatments}

The thoracolumbar DRGs were quickly isolated from young Sprague Dawley female rats (approximately 14 days old) as previously described. ${ }^{20}$ In brief, DRG neurons were dissociated by digestive solution. The cells were seeded onto $18-\mathrm{mm}$ coverslips coated with poly-D-lysine in a culture dish at $37^{\circ} \mathrm{C}$. DRG neurons were cultured in $2 \mathrm{~mL}$ neurobasal media (Gibco; Thermo Fisher Scientific) for 24 hours. The cells were then incubated with VEGF $(10,50$, and $100 \mathrm{ng} / \mathrm{mL}$, SRP4365; MilliporeSigma, Burlington, MA), VEGF $(100 \mathrm{ng} / \mathrm{mL})+$ SU5416 $(10 \mu \mathrm{mol} / \mathrm{L})$ overnight. To investigate the effects of phosphatidylinositol 3-kinase (PI3K)/Akt and mitogen-activated protein kinases (MAPKs) on VEGF-induced neurite outgrowth, the cells were treated overnight with PI3K/Akt inhibitor LY294002 (10 $\mu \mathrm{mol} / \mathrm{L}, 19142$; Sigma-Aldrich), extracellular signalregulated protein kinase (ERK) indirect inhibitor PD98359 (10 $\mu \mathrm{mol} / \mathrm{L}, 2243$; Tocris), p38 inhibitor SB203580 (10 $\mu \mathrm{mol} / \mathrm{L}, 1202$; Tocris), or c-Jun $N$-terminal kinase (JNK) inhibitor SP600125 (10 $\mu \mathrm{mol} / \mathrm{L}, 1496$; Tocris) plus VEGF $(100 \mathrm{ng} / \mathrm{mL})$.

\section{Neurite Outgrowth Analysis Using Tubulin Immunostaining}

To assess the neurite outgrowth, the tubulin immunostaining of DRG neurons was performed according to the authors' previous study. ${ }^{20}$ The DRG neurons were fixed with $4 \%$ paraformaldehyde after treatment and then immunostained using mouse antibody against $\beta$-tubulin (1:1000, T5076; Sigma-Aldrich). For each treatment, 10 sampling fields were 
counted, and a total of 100 cells were assessed. Three independent culture experiments were set up for each condition. The longest neurite length measurement of neurons was performed with Leica application suite version 4.3 software (Leica Microsystems).

\section{Statistical Analysis}

SPSS version 13 software (IBM SPSS, Chicago, IL) was used for statistical evaluation. The data are presented as means \pm SD for in vivo experiments and as means \pm SEM for in vitro experiments. Analysis of variance with post-hoc Turkey's multiple comparisons test and unpaired $t$-test were used to analyze variables from different groups. Correlation test quantified the relationship between nerve density and vascular density. $P<0.05$ was considered to be statistically significant.

\section{Results}

\section{General Characteristics of MNU-Induced Breast Cancer}

Chemically induced breast cancer in female rats by MNU was used in the current study. Almost all of the tumors were initially palpated on months 3 to 4 after the first application of MNU. About $40.6 \%$ (61/150) of the total rats developed grossly detectable tumors. Histopathological examination revealed $100 \%$ incidence of mammary tumors. One, two, and three tumors per rat were found in 24,30 , and 7 rats, respectively. The majority of rats $(88.5 \%, 54 / 61)$ developed one to two breast tumors (Table 1). The tumors were distributed more in the thoracic and abdominal mammary glands (80/105, 76.2\%) than in the cervical and inguinal mammary glands $(25 / 105$, $23.8 \%$ ), as shown in Table 1. Figure $1 \mathrm{~A}$ shows a tumor in the abdominal mammary gland. The average largest diameter of breast tumor was $1.96 \pm 0.72 \mathrm{~cm}$ (range, 0.5 to $3.3 \mathrm{~cm}$ ). Figure 1B shows a representative gross view of a

Table 1 The General Characteristics of MNU-Induced Breast Cancer

\begin{tabular}{lc}
\hline Tumor characteristics & Samples, $n /$ total $(\%)$ \\
\hline Number of tumors/rat & \\
1 & $24 / 61(39.3)$ \\
2 & $30 / 61(49.2)$ \\
3 & $7 / 61(11.5)$ \\
Location of tumors & \\
$\quad$ Thoracic/abdominal mammary glands & $80 / 105(76.2)$ \\
Cervical/inguinal mammary glands & $25 / 105(23.8)$ \\
Histology & \\
Adenoma & $4 / 105(3.8)$ \\
Carcinoma & $101 / 105(96.2)$ \\
$\quad$ Invasive & $93 / 101(92.1)$ \\
$\quad$ In situ & $8 / 101(7.9)$ \\
\hline
\end{tabular}

tumor with a largest diameter of $2.2 \mathrm{~cm}$. Almost all of the breast tumors were identified as carcinomas (101/105, $96.2 \%)$. The majority of the carcinomas were invasive $(93 / 101 ; 92.1 \%)$, as shown in Table 1 . Invasive carcinomas were characterized by their characteristic feature of spreading into the surrounding stroma of epithelial cells like finger, duct, or solid sheets (Figure 1D) compared with normal breast (Figure 1C).

\section{Axonogenesis in Breast Tumors of Rat Induced by MNU}

The authors' previous study provides evidence that axonogenesis occurs in human breast cancer. ${ }^{4}$ To explore its mechanism, existence of whether axonogenesis in breast tumor induced by MNU had to be examined. Immunohistochemistry of paraffin-embedded breast tumors revealed the presence of axonogenesis, either individual PGP9. $5^{+}$nerve fibers (Figure 1E) or bundles (Figure 1F), mainly in the tumor stroma. Immunofluorescence of the frozen breast tumors showed PGP9.5immunoreactive nerve bundles, and sensory (CGRP-positive) and sympathetic (VMAT2-positive) nerve fibers present in the tumor, and PGP9. $.5^{+}$nerve fibers and bundles observed in the normal breast tissue (Figure 2A). Unfortunately, the authors did not find parasympathetic nerves (VAChT-negative) in the tumor (data not shown). Most of the nerves were distributed in the tumor stroma, and some individual fibers accompanied blood vessels (Figure 2B). Another neuronal marker NF was found to be colocalized with PGP9. $5^{+}$nerve bundle in the stroma of breast tumor (Figure 2B). The density of neurites in the breast tumor significantly increased with the development of the tumor such that the density of neurites in tumor was greater at month 3 than at month 2 , as well as greater at month 2 than at month 1, after the tumor was initially palpated. The effects are observed qualitatively by WB bands and immunohistochemical images, and quantitatively by graphs in Figure 2, C and D.

\section{Retrograde Tracing from Breast Tumors}

To determine the DRG sensory neurons innervating breast tumor, the DiI-labeled neurons from T13 to S1 and T3 to T10 DRGs were examined. Thus, fluorescent neural tracer DiI, usually used to investigate the origins of sensory innervations of peripheral organs, was injected into the abdominal and thoracic breast tumors, respectively, at month 2 (from rats 1 to 3 ) and month 3 (from rats 4 to 6) after the induction of tumor. Figure $3, \mathrm{~A}$ and $\mathrm{B}$, provides examples of a tumor grown in the abdominal mammary gland at month 3 after the induction of tumor from rat 4 (Figure 3A) and the other tumor grown in the thoracic mammary gland at month 2 after the induction of tumor from rat 1 (Figure 3B). Injection of DiI into the breast tumor labeled nerve fibers, with intense red fluorescence from rat 4 (Figure 3C) and rat 1 (Figure 3D). After 


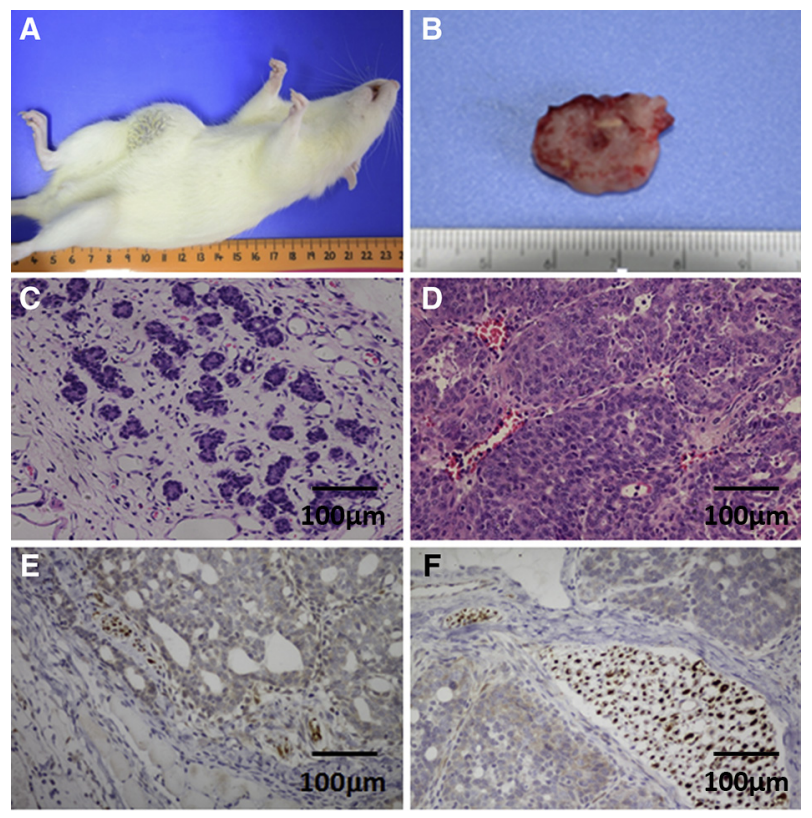

Figure 1 The expression of PGP9.5 in MNU-incuded breast tumor in rat. A: Example of a tumor grown in the abdominal mammary gland in a female Sprague Dawley rat. B: Example of the gross view of the excised tumor. C: Histology of a normal mammary gland. D: Representative solid pattern of hematoxylin and eosin staining indicating neoplastic cells with prominent nuclei and poorly defined cell limits forming a continuous sheet. E: Scattered PGP9.5-immunoreactive nerve fibers in tumor stroma of breast cancer. F: PGP9.5-immunoreactive nerve bundles in tumor stroma of breast cancer. Scale bars $=100 \mu \mathrm{m}(\mathbf{C}-\mathbf{F})$.

application of DiI into the abdominal and thoracic breast tumors, neurons labeled with DiI were evident in sectioned lumbar (peaked at L1 to L2) and thoracic (peaked at T5 to T6) DRGs, respectively. Figure 3, E and F show DiIlabeled neurons at peak L1 and T5 DRGs from rat 4 and rat 1 , respectively. The number of DiI-labeled neurons at peak DRGs from rats 1 to 6 is shown in Figure 3G. The number of Dil-labeled neurons was much greater at month 3 than at month 2 after induction of tumor, shown qualitatively by micrographs in Figure 3, E and F, and quantitatively by the graph in Figure $3 \mathrm{H}$.

\section{Contribution of VEGF and NGF to Axonogenesis in Breast Tumors}

To determine the role of VEGF, as well as NGF in the axonogenesis of breast tumors, the change in VEGF and NGF levels within the breast tumor were first examined at months 1, 2, and 3 after induction of tumor using enzymelinked immunosorbent assay. The protein levels of either VEGF or NGF differed significantly by the time the tumor had established. These differences are illustrated in Figure 4, $\mathrm{A}$ and B. There was more of either VEGF or NGF at month 3 than at month 2 , and more at month 2 than at month 1 after induction of tumor.
Evidence shows that nerve fiber infiltration into the tumor microenvironment is associated with nerve growth factor production in breast cancer, ${ }^{13}$ and the results of the current study suggest that axonogenesis is correlated with angiogenesis in human breast cancer. ${ }^{4}$ To investigate whether VEGF and NGF are involved in the axonogenesis of breast tumor, PGP9.5 expression of breast tumor was examined following VEGFR inhibitor, anti-VEGFR2 antibody, and NGFR inhibitor treatments (Figure 4B). Intraperitoneal injection of either VEGFR/NGFR inhibitor SU5416/AG879 $(1 \mathrm{mg} / \mathrm{kg}$, every other day for a month) or anti-VEGFR2 antibody $(5 \mu \mathrm{g} / \mathrm{kg}$, twice a week for a month) starting at month 4 after first injection of MNU is illustrated in Figure 4C. All of the densities of PGP9.5 in breast tumors from rats treated with SU5416, AG879, and anti-VEGFR2 antibody were much weaker than those in rats treated with the vehicle. The effects induced by these treatments are indicated qualitatively by WB bands and immunohistochemical images, and quantitatively by graphs in Figure 4, $\mathrm{C}$ and $\mathrm{D}$. In addition, all these drugs reduced the vascular density in the breast tumor (Figure 4, E and F), and the decreased nerve density was correlated with reduced vascular density (Figure 4G).

\section{Effects of PI3K/Akt and MAPKs Inhibitors on VEGF- Induced Neurite Elongation of DRG Neurons}

To examine the effects of VEGF on neurite outgrowth of DRG neurons, primary DRG neurons were cultured for 24 hours and then incubated with VEGF plus VEGFR inhibitor. In DRG neurons were incubated with VEGF (10, 50 , and $100 \mathrm{ng} / \mathrm{mL}$ ) overnight, the length of the neurite was increased compared with control in a dose-dependent manner. As expected, application of SU5416, the VEGFR inhibitor, reversed the effect of VEGF, as shown in Figure 5, A and B.

To further examine the involvement of the PI3K/Akt and MAPKs in VEGF-induced neurite outgrowth, PI3K/Akt inhibitor LY294002, ERK indirect inhibitor PD98059 (10 $\mu \mathrm{mol} / \mathrm{L})$, p38 inhibitor SB203580 $(10 \mu \mathrm{mol} / \mathrm{L})$, or JNK inhibitor SP600125 $(10 \mu \mathrm{mol} / \mathrm{L})$ were given followed by VEGF (100 ng/mL). Both LY294002 and PD98059 substantially inhibited VEGF-elevated length of axon. Similarly SB203580 significantly attenuated neurite outgrowth induced by VEGF. However, SP600125 had no effect on VEGF-increased length of axon (Figure 5, A and $\mathrm{C}$ ). Alone, none of the inhibitors changed neurite outgrowth (data not shown).

\section{Discussion}

The existence of nerves in the microenvironment of breast cancer from human specimens is demonstrated by the authors and other., ${ }^{4,13,21}$ These studies indicate that infiltration of nerves into the microenvironment of breast 
A
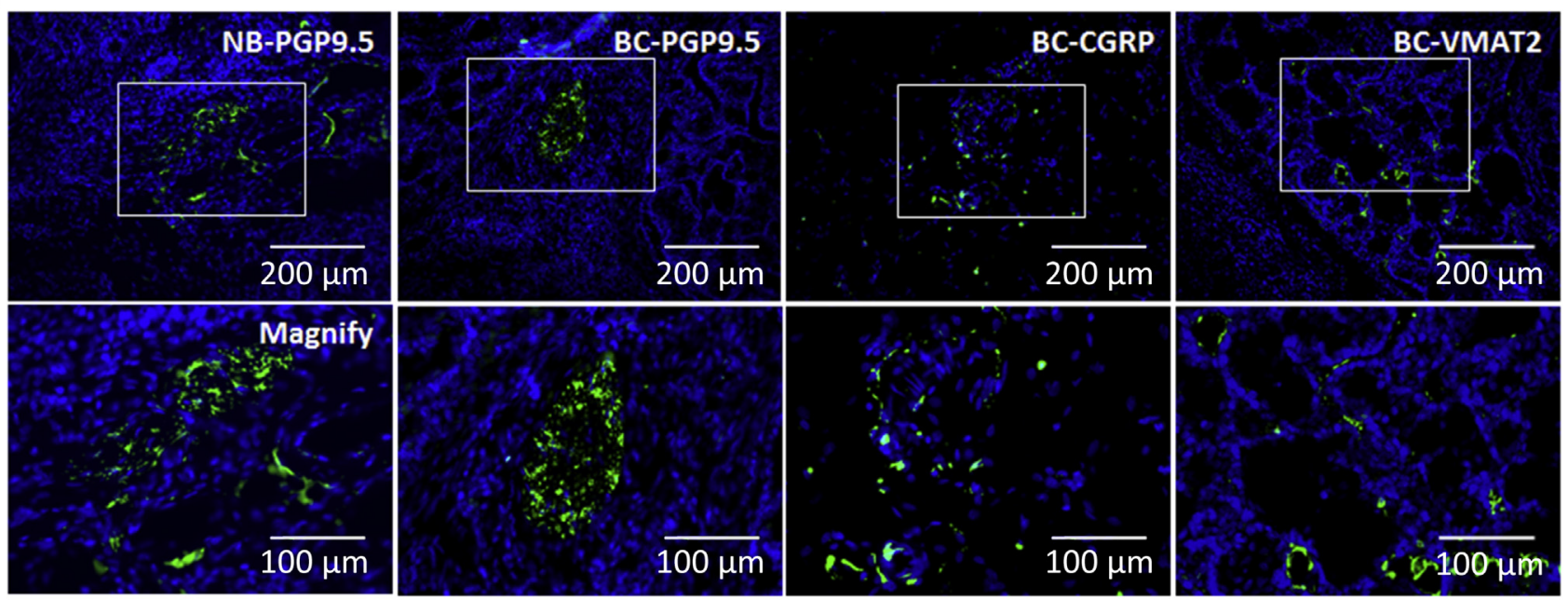

B

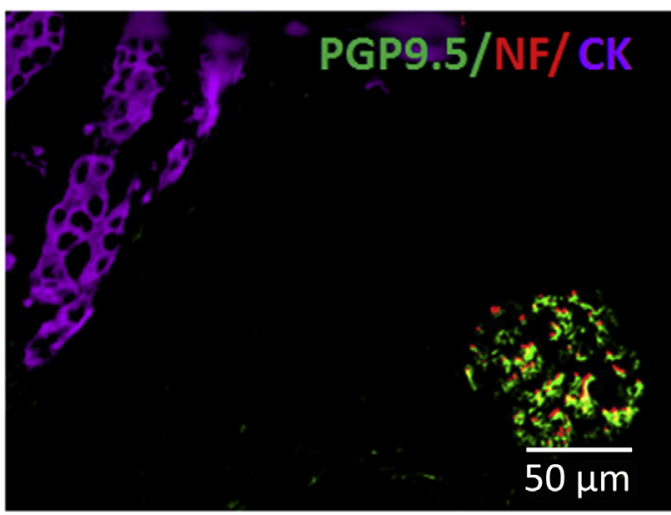

C
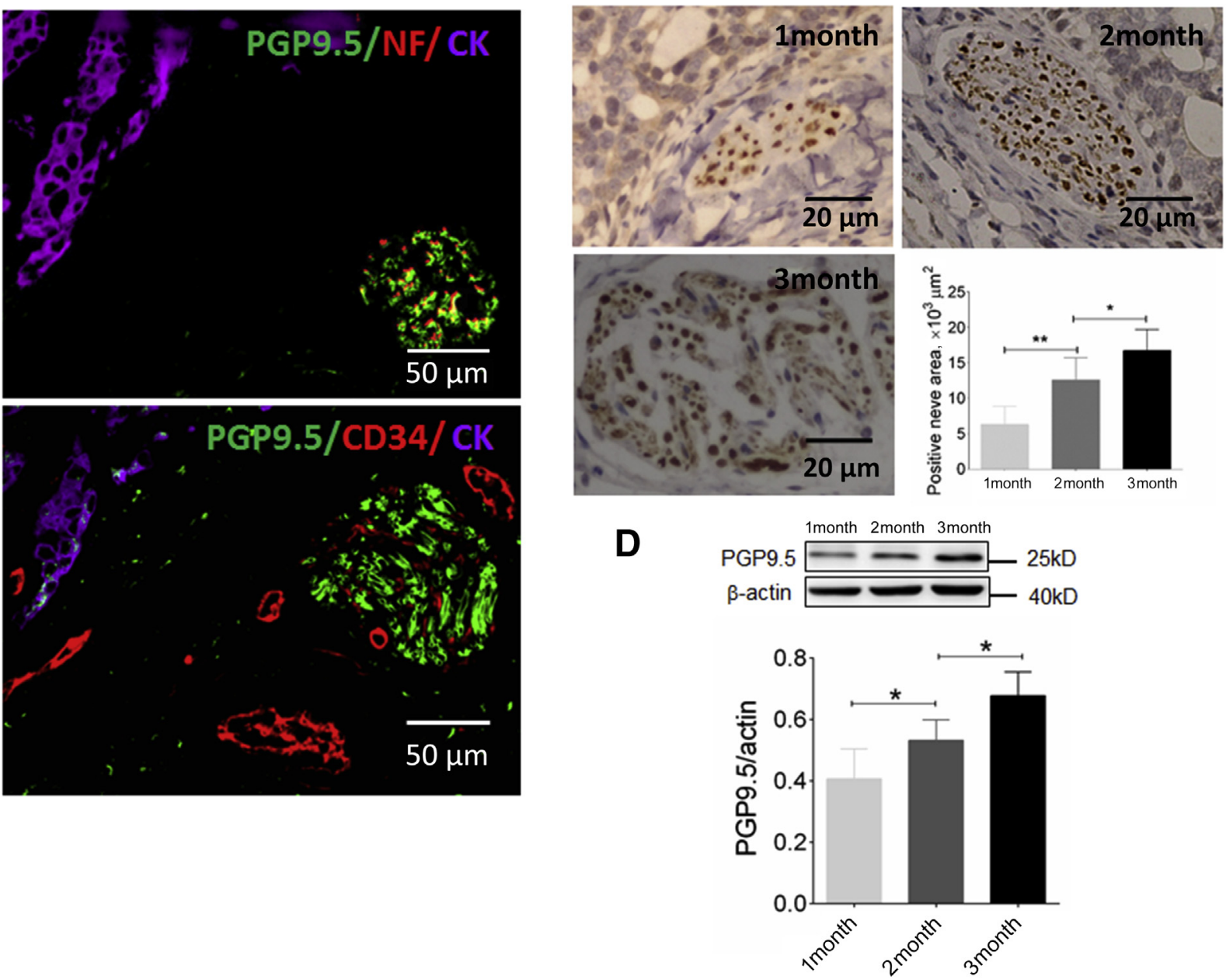

Figure 2 Different types of nerve infiltration into MNU-induced breast tumor in rat. A: Representative microphotographs of immunofluorescence (IF) staining of nerve fibers (PGP 9.5 $5^{+}$including sensory $\left(\mathrm{CGRP}^{+}\right)$and sympathetic $\left(\mathrm{VMAT2}{ }^{+}\right)$nerve fibers in normal breast tissue and mammary tumor. Boxed areas are shown at higher magnification below. B: Representative images of multiplex IF staining of nerve fibers (PGP9.5 $5^{+}$or NF$\left.{ }^{+}\right)$, blood vessels $\left(\mathrm{CD}^{2} 4^{+}\right)$, and tumor epithelium $\left(\mathrm{CK}^{+}\right)$in mammary tumor. $\mathbf{C}$ and $\mathbf{D}$ : The positive nerve area occupied by PGP9. $5^{+}$nerve bundles was higher (C) and the protein level of PGP9.5 was greater (D) in breast tumor at month 2 than at month 1 , as well as at month 3 compared with month 2 after tumor induction. ${ }^{*} P<0.05$, ${ }^{* *} P<0.01$ (oneway analysis of variance with Tukey multiple comparison test). Scale bars: $200 \mu \mathrm{m}$ (A, top row); $100 \mu \mathrm{m}$ (A, bottom row); $50 \mu \mathrm{m}(\mathbf{B}) ; 20 \mu \mathrm{m}(\mathbf{C}), \mathrm{BC}$, breast cancer; NB, normal breast. 

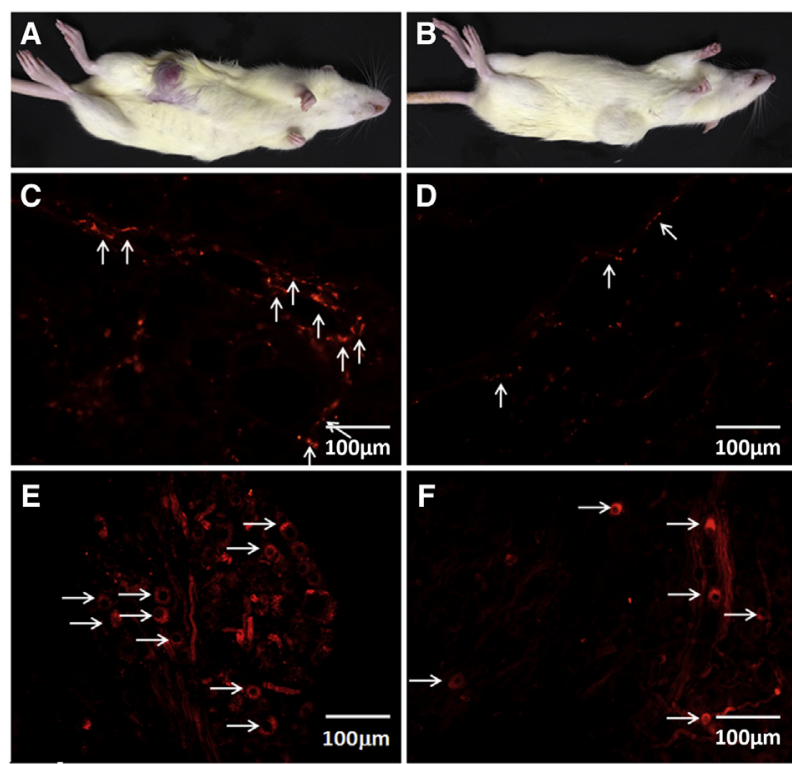

G

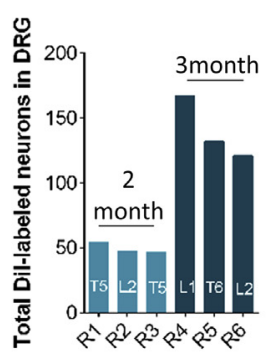

H

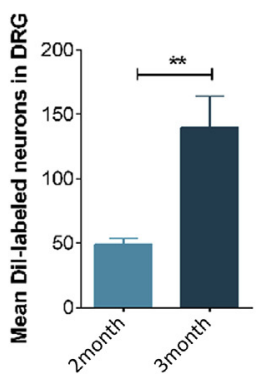

Figure 3 The distribution of sensory neurons in dorsal root ganglions (DRGs) filled by DiI as seen in the MNU-induced breast tumors in rat (R). A: Tumor grown in abdominal mammary gland at month 3 after initial palpation in rat 4 (R4). B: Tumor grown in thoracic mammary gland at month 2 after initial palpation in rat 1 (R1). C and D: DiI-labeled nerve fibers in tumors of breast cancer from rat 4 and rat 1 , respectively. Arrows indicate DiI-labeled nerve fibers. $\mathbf{E}$ and $\mathbf{F}$ : DiI-labeled sensory neurons at peak L1 (E) and T5 (F) DRG from rat 4 and rat 1, respectively. Arrows indicate DiI-labeled sensory neurons. G: The mean DiI-labeled sensory neurons at different peak segments of DRG from rat 1 to 6 . H: The were many more DiI-labeled neurons in DRG at month 3 than at month 2 after tumor induction. ${ }^{* *} P<0.01$ (unpaired $t$-test). Scale bars $=100 \mu \mathrm{m}$ (C-F).

tumors is related to breast cancer progression such as lymph node invasion, tumor grade, higher clinical stage, and patient's outcome. This underscores the need to investigate the mechanisms of axonogenesis in breast cancer. This prompted us to look for an experimental model that can mimic the complex interactions that occur in patients with breast cancer. MNU is a carcinogenic chemical causing the formation of neoplastic lesions that share common features with their human counterparts. ${ }^{22,23}$ Therefore, MNUinduced model of breast cancer has been used broadly to evaluate drugs to prevent and cure human breast cancer. ${ }^{24-26}$ The current study demonstrates that axonogenesis occurs in an experimental breast cancer model induced by MNU. All of the samples were selected from the superficial layer of breast tumor $(5 \mathrm{~mm} \times 5 \mathrm{~mm})$ because nerve fibers were mainly found in the superficial, but not in the deep layer of breast tumors in the preliminary experiment. Both the immunohistochemical and immunofluorescent stains showed the presence of either PGP9. $5^{+}$single-nerve fiber or nerve bundle in the tumor stroma. Furthermore, the sensory $\left(\mathrm{CGRP}^{+}\right)$and sympathetic nerve fibers $\left(\mathrm{VMAT2}^{+}\right)$had sprouted into the breast tumors, while some surrounded the blood vessels. Interestingly, parasympathetic nerve fibers $\left(\mathrm{VAChT}^{+}\right)$were not found in the breast tumor. However, parasympathetic innervations of breast tumor can not be excluded because one study showed the presence of parasympathetic nerves in the breast tumor. ${ }^{27}$ The failure of VAChT immunostaining is probably due to the limitation of antibody used here. More importantly, that the density of PGP9.5 was higher with tumor growth, supported by WB and immunohistochemistry. Thus, this experimental model of MNU-induced breast cancer is suitable for further study. The authors plan to use it to investigate the mechanisms of axonogenesis and the biological significance of axonogenesis in breast cancer.

To confirm that sensory nerve fibers sprout into the breast tumor, retrograde tracing techniques were used. Injection of DiI into the abdominal and thoracic breast tumors indicated the presence of DiI-labeled DRG neurons. The abdominal mammary tumors were innervated by sensory neurons from rostral T12 to caudal S1 DRG, and peaked at L1 to L2 DRG. On the other hand, the thoracic mammary tumors were innervated by sensory neurons from T3 to T10 DRG and peaked at T5 to T6 DRG. These observations suggest that sensory neurons that innervated the abdominal and thoracic mammary tumors differ in a number of characteristics. Thus, it would be helpful to investigate the functions of sensory neurons innervating the breast tumors in future studies. In addition, the number of DiI-labeled neurons in DRG increased as the tumor developed. Besides sensory nerve fibers, sympathetic nerve fibers were also observed in breast tumor. Beta-adrenergic receptor blockers can reduce recurrence rates and mortality in patients with breast cancer. $^{28-30}$ These blockers decrease the effect of catecholamines, which might be released by sympathetic nerves locally within the breast tumor. In agreement with the authors' findings, one study demonstrated that the sympathetic nerves innervate breast tumors, which accelerate tumor progression either in xenografts of human breast cancer cells or in breast cancer induced by chemicals. ${ }^{27}$

In prostate cancer, nerve infiltration may be driven by the production of proNGF ${ }^{12}$ and G-CSF. ${ }^{10}$ NGF is higher in breast cancer cells, which leads to the autocrine stimulation of breast cancer cells via the tyrosine kinase receptor TrkA and the TNF-receptor family member $\mathrm{p} 75^{\mathrm{NTR}} .3^{1,32}$ In addition, the presence of nerve fibers in the microenvironment of human breast tumor is associated with the production of NGF. ${ }^{13}$ However, there is no direct evidence that NGF contributes to axonogenesis in breast tumor. The present study demonstrates an increase in the expression of 
A
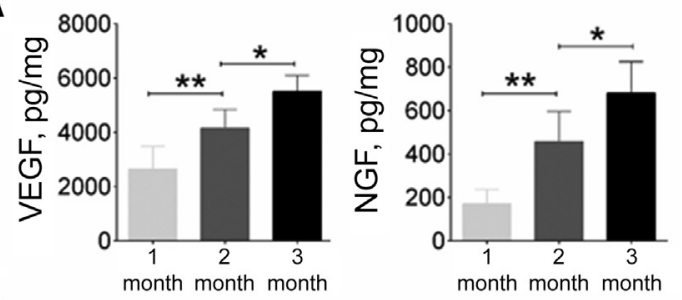

C
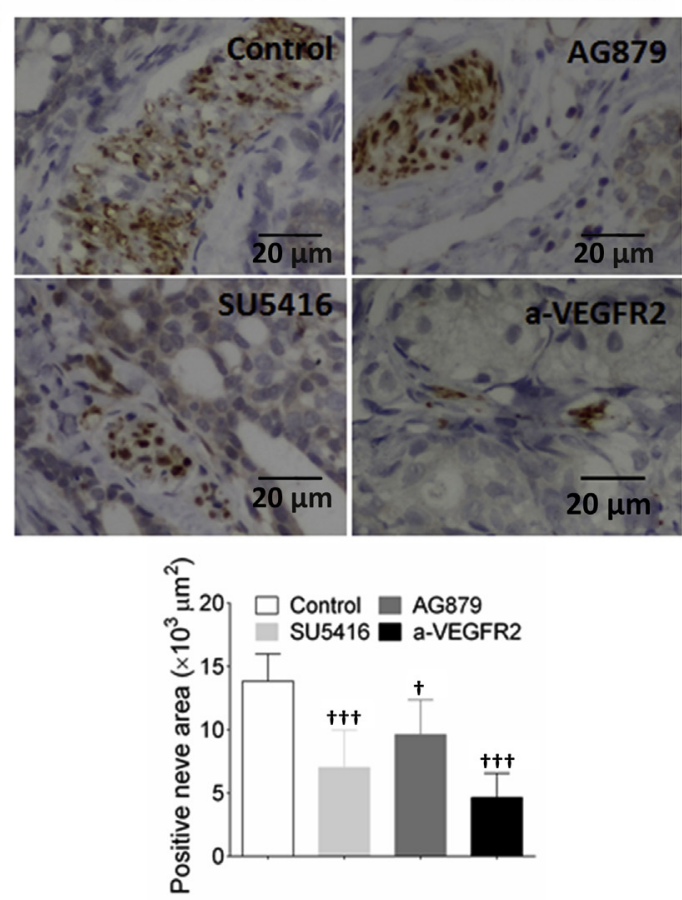

E

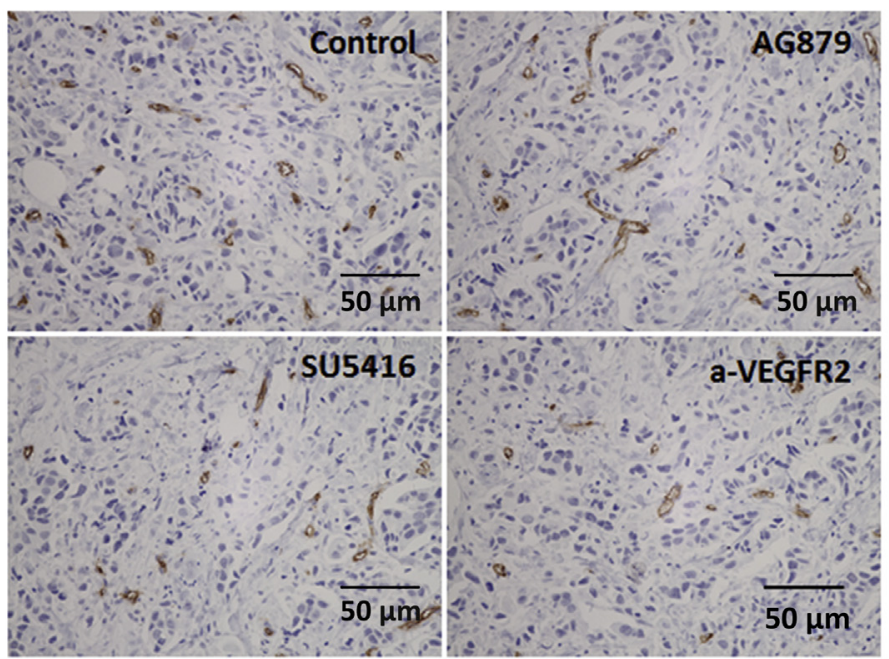

B

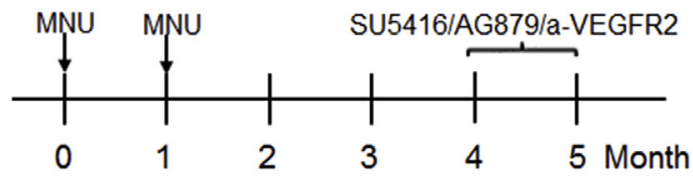

D
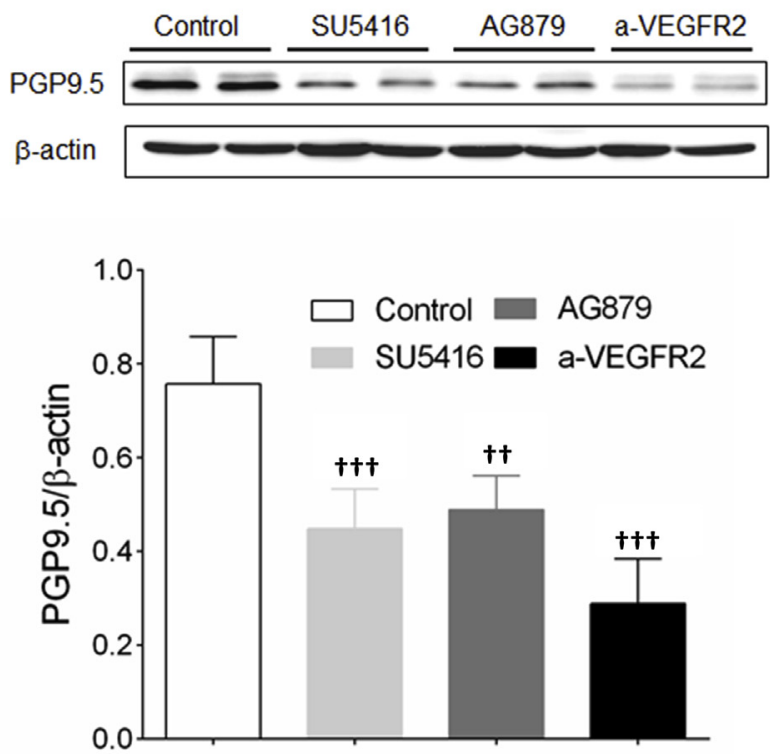

F

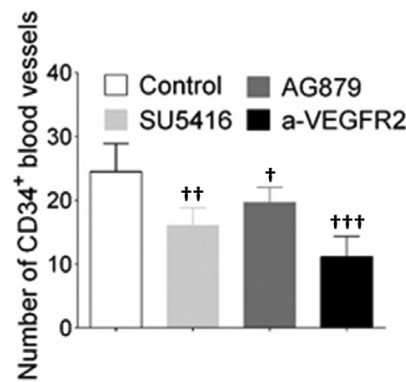

G

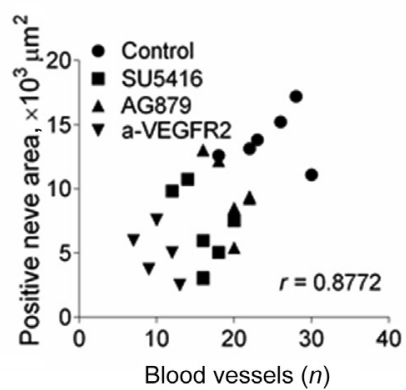

Figure 4 The effects of inhibition of VEGF, as well as NGF receptor, on expression of PGP9.5 and CD34 in breast tumor. A: The level of VEGF and NGF was increased following the development of breast tumor, at months 1, 2, and 3 after tumor was initially palpated. B: Timeline for MNU-induced breast tumor development and therapeutic schedule for treatments with VEGF receptor (Flk-1) inhibitor SU5416, NGF receptor (TrkA) inhibitor AG879, and anti-VEGF receptor 2 antibody (a-VEGFR2). C and D: Expression of PGP9.5 was significantly decreased by SU5416, AG879, and a-VEGFR2. E and F: Number of CD34 ${ }^{+}$ blood vessels was apparently reduced by SU5416, AG879, and a-VEGFR2. G: Scattered plots showing the correlation between positive nerve area and the number of blood vessels in breast tumor affected by the treatments in B. ${ }^{*} P<0.05,{ }^{*}{ }^{*} P<0.01$ (one-way analysis of variance with Tukey multiple comparisons test) ${ }^{\dagger} P<0.05,{ }^{\dagger \dagger} P<0.01$, and ${ }^{\dagger \dagger} P<0.001$ versus control (one-way analysis of variance with Tukey multiple comparisons test). Scale bars: $20 \mu \mathrm{m}$ (C); $50 \mu \mathrm{m}$ (E). 


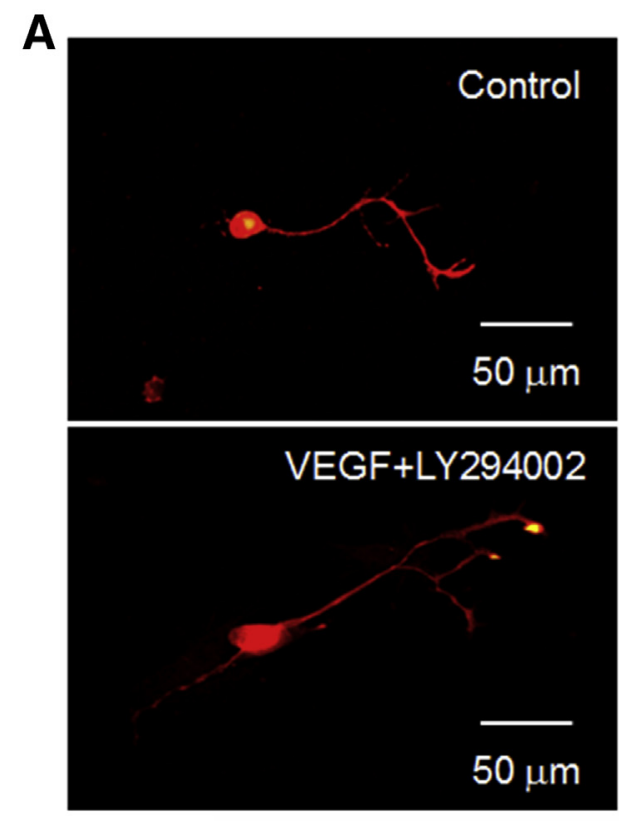

B

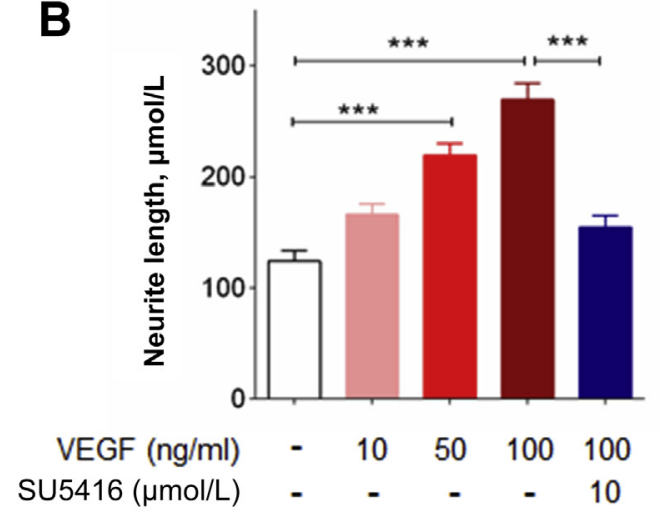

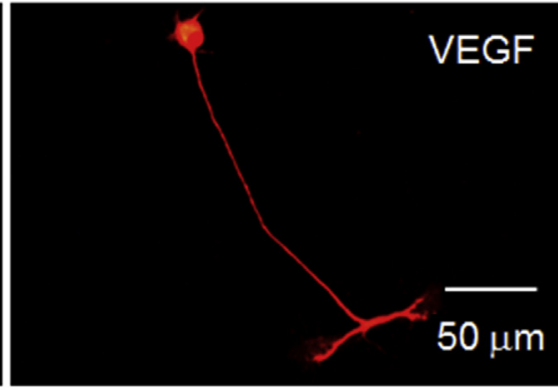
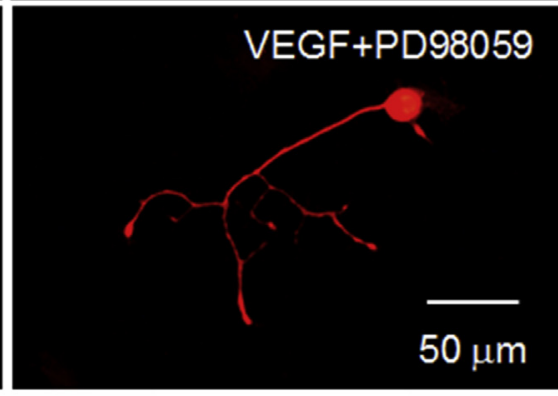

C

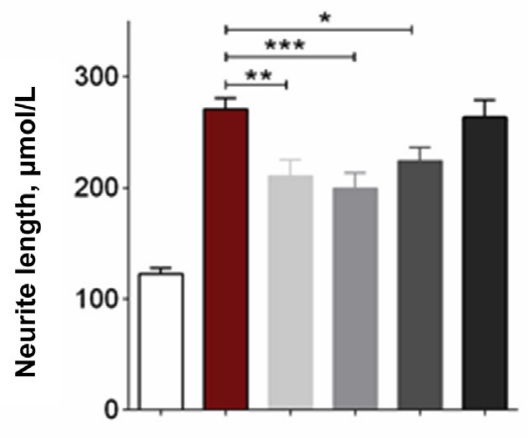

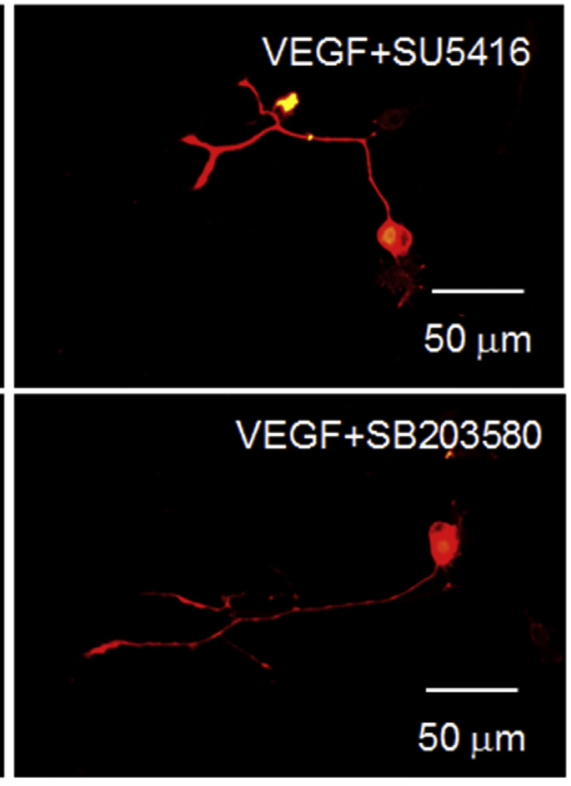

$50 \mu \mathrm{m}$

Figure 5 The effects of PI3K/Akt and MAPKs on VEGF-induced neurite outgrowth of cultured dorsal root ganglion (DRG) neurons. A: Representative microphotographs of neuronal morphology using immunostaining with tubulin following various treatments. B: Effects of VEGF on the neurite outgrowth of DRG neurons. VEGF dose-dependently increases neurite length and VEGF receptor inhibitor SU5416 $(10 \mu \mathrm{mol} / \mathrm{L})$ reverses the effects induced by VEGF (100 ng/ $\mathrm{mL}$ ). C: Effects of MAPK inhibitors on the VEGF-induced neurite elongation. PI3K/Akt inhibitor LY294002, ERK indirect inhibitor PD98059 (10 $\mu \mathrm{mol} / \mathrm{L})$, and $\mathrm{p} 38$ inhibitor SB203580 $(10 \mu \mathrm{mol} / \mathrm{L})$ significantly attenuate VEGF-induced neurite elongation, but JNK inhibitor SP600125 (10 $\mu \mathrm{mol} / \mathrm{L})$ does not affect VEGFmediated neurite outgrowth. ${ }^{*} P<0.05,{ }^{*} P<0.01$, and ${ }^{* * *} P<0.001$ (one-way analysis of variance with Tukey multiple comparisons test). Scale bars $=50 \mu \mathrm{m}$.

NGF as the tumor develops and a significant reduction in the nerve density by chronic tyrosine kinase receptor TrkA inhibitor AG879. These findings suggest NGF partially contributes to the sprouting of nerve fibers into the breast tumor through TrkA.

Besides NGF, other growth factors are produced in breast cancer. ${ }^{33-35}$ Particularly, the authors propose that VEGF, which plays a neurotrophic role, may contribute to the axonogenesis in breast cancer because the authors' previous study demonstrated that axonogenesis is correlated with angiogenesis in human breast tumor. ${ }^{4}$ Here, both rat model and cell cultures were used to verify the hypothesis that the innervation of breast tumor is regulated by VEGF. At first, the authors demonstrated that the level of VEGF in breast tumor increased as the tumor grew. In addition, it was found that either VEGFR-2 blockage by inhibitor SU5416 or VEGFR-2 neutralization by antiVEGFR2 antibody significantly reduced the densities of PGP9.5 in breast tumor as shown by WB and immunohistochemistry. These results indicate that VEGF may account for the axonogenesis of breast cancer through VEGFR-2 (Flk-1). VEGFR-2 has been implicated in neurogenesis in previous studies in which overexpression of a mutant VEGFR-2 induced less basal neurogenesis and 
weakened learning, ${ }^{36}$ and antidepressant therapy promoted neurogenesis through up-regulation of VEGF and downstream VEGFR-2 in the hippocampus. ${ }^{37}$

The presence of VEGF and its receptors has been demonstrated in sensory neurons, ${ }^{38}$ and VEGF has been shown to promote neurite outgrowth. ${ }^{39}$ The current study indicates the innervation of breast tumor by sensory nerves from DRG. Thus, the role of VEGF/VEGFR-2 signaling in neurite outgrowth was examined using cultured DRG from 14-day-old rats in which the level of VEGF/VEGFR-2 in DRG was similar to that of adult DRG. ${ }^{38}$ The authors found that VEGF triggered the axon elongation of DRG neurons, and VEGFR-2 inhibitor reversed VEGF-induced neurite outgrowth. These results are in agreement with a previous study in which VEGFR2 participated in VEGF-induced axonal outgrowth. ${ }^{40}$ Furthermore, VEGFR-1 and VEGFR-2 are expressed in postganglionic neurons. VEGF has been shown to promote vascular innervation via VEGFR-2. ${ }^{41,42}$ Taken together, VEGF possibly contributes to the innervation of breast tumor by either sensory nerves or sympathetic nerves. However, the possible effect of VEGFR-1 on the axonogenesis of breast cancer cannot be excluded because of the presence of VEGFR-1 in sensory neurons and postganglionic sympathetic neurons. ${ }^{41-43}$

Activation of VEGFR2 induces axon outgrowth through several signaling pathways. Stimulation of VEGFR-2-activated PI3K/Akt leads to axon growth in subicular neurons. ${ }^{44}$ An in vitro experiment has suggested that VEGF regulates growth cone turning of commissural axon via locally activated Src family kinases. ${ }^{45}$ The activation of VEGFR-2, P13K/Akt, and mitogenactivated protein kinase kinase (MEK) is required for VEGF-induced neurite outgrowth. ${ }^{17}$ The authors' data indicates that PI3K/Akt, ERK, and p38 inhibitors, instead of the JNK inhibitor, decrease VEGF-induced neurite outgrowth of DRG neurons. Both in vivo and in vitro findings here suggest that VEGFR-2 mediates axonogenesis in the breast tumor and axon elongation of DRG neurons innervating the breast tumor in part via PI3K/ Akt, ERK, and p38 signaling pathways. Furthermore, there is evidence that VEGF guides commissural axon crossing at the optic chiasm through nontyrosine kinase receptor of the neuropilin. ${ }^{46}$ Taken together, VEGF acts as axon growth and navigation factor via different receptors and mechanisms relying on the neuronal type and developmental process.

The authors' work from an experimental model of breast cancer demonstrates that sprouted nerve fibers, including both sensory and sympathetic nerves, are present in breast tumor. Pharmacological blockage or neutralization of VEGFR-2, as well as blockage of NGF receptor TrkA, leads to a decrease in nerve densities of breast tumor. In addition, activation of VEGFR-2 and its downstream PI3K/Akt, ERK, and p38 signals may account for innervations from DRG neurons into breast tumor. The authors' results imply that inactivation of VEGFR-2 and its downstream PI3K/ Akt, ERK, and p38 signals may postpone the process of sprouted innervation related to the progression of breast cancer.

\section{Author Contributions}

H.H., C.Y. and Y.Z. performed experiments and analyzed data; C.H. performed the experiments and wrote the manuscript; H.H. and G.Z. supervised the study and wrote the manuscript; all authors approved the final manuscript.

\section{References}

1. Ayala GE, Dai H, Powell M, Li R, Ding Y, Wheeler TM, Shine D, Kadmon D, Thompson T, Miles BJ, Ittmann MM, Rowley D: Cancerrelated axonogenesis and neurogenesis in prostate cancer. Clin Cancer Res 2008, 14:7593-7603

2. Olar A, He D, Florentin D, Ding Y, Ayala G: Biologic correlates and significance of axonogenesis in prostate cancer. Hum Pathol 2014, 45:1358-1364

3. Albo D, Akay CL, Marshall CL, Wilks JA, Verstovsek G, Liu H, Agarwal N, Berger DH, Ayala GE: Neurogenesis in colorectal cancer is a marker of aggressive tumor behavior and poor outcomes. Cancer 2011, 117:4834-4845

4. Zhao Q, Yang Y, Liang X, Du G, Liu L, Lu L, Dong J, Han H, Zhang G: The clinicopathological significance of neurogenesis in breast cancer. BMC Cancer 2014, 14:484

5. He D, Manzoni A, Florentin D, Fisher W, Ding Y, Lee M, Ayala G: Biologic effect of neurogenesis in pancreatic cancer. Hum Pathol 2016, 52:182-189

6. Zhang L, Guo L, Tao M, Fu W, Xiu D: Parasympathetic neurogenesis is strongly associated with tumor budding and correlates with an adverse prognosis in pancreactic ductal adenocarcinoma. Chin J Cancer Res 2016, 28:180-186

7. Magnon C, Hall SJ, Lin J, Xue X, Gerber L, Freedland SJ, Frenette PS: Autonomic nerve development contributes to prostate cancer progression. Science 2013, 341:1236361

8. Zhao C-M, Hayakawa Y, Kodama Y, Muthupalani S, Westphalen CB, Andersen GT, Flatberg A, Johannessen H, Friedman RA, Renz BW, Sandvik AK, Beisvag V, Tomita H, Hara A, Quante M, Li Z, Gershon MD, Kaneko K, Fox JG, Wang TC, Chen D: Denervation suppresses gastric tumorigenesis. Sci Transl Med 2014, 6:250ra115

9. Mauffrey P, Tchitchek N, Barroca V, Bemelmans AP, Firlej V, Allory Y, Roméo PH, Magnon C: Progenitors from the central nervous system drive neurogenesis in cancer. Nature 2019, 569: 672-678

10. Dobrenis K, Gauthier LR, Barroca V, Magnon C: Granulocyte colony-stimulating factor off-target effect on nerve outgrowth promotes prostate cancer development. Int J Cancer 2015, 136: 982-988

11. Hayakawa Y, Sakitani K, Konishi M, Asfaha S, Niikura R, Tomita H, Renz BW, Tailor Y, Macchini M, Middelhoff M, Jiang Z, Tanaka T, Dubeykovskaya ZA, Kim W, Chen X, Urbanska AM, Nagar K, Westphalen CB, Quante M, Lin C-S, Gershon MD, Hara A, Zhao CM, Chen D, Worthley DL, Koike K, Wang TC: Nerve growth factor promotes gastric tumorigenesis through aberrant cholinergic signaling. Cancer Cell 2017, 31:21-34

12. Pundavela J, Demont $\mathrm{Y}$, Jobling $\mathrm{P}$, Lincz LF, Roselli $\mathrm{S}$, Thorne RF, Bond D, Bradshaw RA, Walker MM, Hondermarck H: ProNGF correlates with Gleason score and is a potential driver of 
nerve infiltration in prostate cancer. Am J Pathol 2014, 184: $3156-3162$

13. Pundavela J, Roselli S, Faulkner S, Attia J, Scott RJ, Thorne RF, Forbes JF, Bradshaw RA, Walker MM, Jobling P, Hondermarck $\mathrm{H}$ : Nerve fibers infiltrate the tumor microenvironment and are associated with nerve growth factor production and lymph node invasion in breast cancer. Mol Oncol 2015, 9: $1626-1635$

14. Guaiquil VH, Pan Z, Karagianni N, Fukuoka S, Alegre G, Rosenblatt MI: VEGF-B selectively regenerates injured peripheral neurons and restores sensory and trophic functions. Proc Natl Acad Sci U S A 2014, 111:17272-17277

15. Schlau M, Terheyden-Keighley D, Theis V, Mannherz HG, Theiss C: VEGF triggers the activation of cofilin and the Arp2/3 complex within the growth cone. Int J Mol Sci 2018, $19: 384$

16. Castillo X, Melo Z, Varela-Echavarría A, Tamariz E, Aroña RM, Arnold E, Clapp C, Martínez de la Escalera G: Vasoinhibin suppresses the neurotrophic effects of VEGF and NGF in newborn rat primary sensory neurons. Neuroendocrinology 2018, 106: $221-233$

17. Rosenstein JM, Mani N, Khaibullina A, Krum JM: Neurotrophic effects of vascular endothelial growth factor on organotypic cortical explants and primary cortical neurons. J Neurosci 2003, 23: 11036-11044

18. Fournier NM, Lee B, Banasr M, Elsayed M, Duman RS: Vascular endothelial growth factor regulates adult hippocampal cell proliferation through MEK/ERK- and PI3K/AKT-dependent signaling. Neuropharmacology 2012, 63:642-652

19. Imaoka T, Nishimura M, Doi K, Tani S, Ishikawa K, Yamashita S, Ushijima T, Imai T, Shimada Y: Molecular characterization of cancer reveals interactions between ionizing radiation and chemicals on rat mammary carcinogenesis. Int J Cancer 2014, 134: $1529-1538$

20. Han H, Liang X, Wang J, Zhao Q, Yang M, Rong W, Zhang G: Cannabinoid receptor 1 contributes to sprouted innervation in endometrial ectopic growth through mitogen-activated protein kinase activation. Brain Res 2017, 1663:132-140

21. Huang D, Su S, Cui X, Shen X, Zeng Y, Wu W, Chen J, Chen F, He C, Liu J, Huang W, Liu Q, Su F, Song E, Ouyang N: Nerve fibers in breast cancer tissues indicate aggressive tumor progression. Medicine (Baltimore) 2014, 93:e172

22. Rivera ES, Andrade N, Martin G, Melito G, Cricco G, Mohamad N, Davio C, Caro R, Bergoc RM: Induction of mammary tumors in rat by intraperitoneal injection of NMU: histopathology and estral cycle influence. Cancer Lett 1994, 86:223-228

23. Chan MM, Lu X, Merchant FM, Iglehart JD, Miron PL: Gene expression profiling of NMU-induced rat mammary tumors: cross species comparison with human breast cancer. Carcinogenesis 2005, 26:1343-1353

24. Badawi AF, Eldeen MB, Liu Y, Ross EA, Badr MZ: Inhibition of rat mammary gland carcinogenesis by simultaneous targeting of cyclooxygenase-2 and peroxisome proliferator-activated receptor gamma. Cancer Res 2004, 64:1181-1189

25. Roomi MW, Roomi NW, Ivanov V, Kalinovsky T, Niedzwiecki A, Rath M: Modulation of N-methyl-N-nitrosourea induced mammary tumors in Sprague-Dawley rats by combination of lysine, proline, arginine, ascorbic acid and green tea extract. Breast Cancer Res 2005, 7:R291-R295

26. Giles ED, Jindal S, Wellberg EA, Schedin T, Anderson SM, Thor AD, Edwards DP, MacLean PS, Schedin P: Metformin inhibits stromal aromatase expression and tumor progression in a rodent model of postmenopausal breast cancer. Breast Cancer Res 2018, 20:50

27. Barron TI, Connolly RM, Sharp L, Bennett K, Visvanathan K: Beta blockers and breast cancer mortality: a population- based study. J Clin Oncol 2011, 29:2635-2644
28. Cardwell CR, Coleman HG, Murray LJ, Entschladen F, Powe DG: Beta-blocker usage and breast cancer survival: a nested case-control study within a UK clinical practice research datalink cohort. Int J Epidemiol 2013, 42:1852-1861

29. Shaashua L, Shabat-Simon M, Haldar R, Matzner P, Zmora O, Shabtai M, Sharon E, Allweis T, Barshack I, Hayman L, Arevalo J, Ma J, Horowitz M, Cole S, Ben-Eliyahu S: Perioperative COX-2 and $\beta$-adrenergic blockade improves metastatic biomarkers in breast cancer patients in a phase-II randomized trial. Clin Cancer Res 2017, 23:4651-4661

30. Kamiya A, Hayama Y, Kato S, Shimomura A, Shimomura T, Irie K, Kaneko R, Yanagawa Y, Kobayashi K, Ochiya T: Genetic manipulation of autonomic nerve fiber innervation and activity and its effect on breast cancer progression. Nat Neurosci 2019, 22: $1289-1305$

31. Adriaenssens E, Vanhecke E, Saule P, Mougel A, Page A, Romon R, Nurcombe V, Le Bourhis X, Hondermarck H: Nerve growth factor is a potential therapeutic target in breast cancer. Cancer Res 2008, 68: $346-351$

32. Adriaenssens E, Vanhecke E, Saule P, Mougel A, Page A, Romon R, Nurcombe V, Le Bourhis X, Hondermarck H: TrkA overexpression enhances growth and metastasis of breast cancer cells. Oncogene 2009, 28:1960-1970

33. Tsai YF, Tseng LM, Hsu CY, Yang MH, Chiu JH, Shyr YM: Brain-derived neurotrophic factor (BDNF) -TrKB signaling modulates cancer-endothelial cells interaction and affects the outcomes of triple negative breast cancer. PLoS One 2017, 12: e0178173

34. Vanhecke E, Adriaenssens E, Verbeke S, Meignan S, Germain E, Berteaux N, Nurcombe V, Le Bourhis X, Hondermarck H: Brainderived neurotrophic factor and neurotrophin- $4 / 5$ are expressed in breast cancer and can be targeted to inhibit tumor cell survival. Clin Cancer Res 2011, 17:1741-1752

35. Piasecka D, Braun M, Kitowska K, Mieczkowski K, Kordek R, Sadej R, Romanska H: FGFs/FGFRs-dependent signalling in regulation of steroid hormone receptors - implications for therapy of luminal breast cancer. J Exp Clin Cancer Res 2019, $38: 230$

36. Cao L, Jiao X, Zuzga DS, Liu Y, Fong DM, Young D, During MJ: VEGF links hippocampal activity with neurogenesis, learning and memory. Nat Genet 2004, 36:827-835

37. Warner-Schmidt JL, Duman RS: VEGF as a potential target for therapeutic intervention in depression. Curr Opin Pharmacol 2008, 8: 14-19

38. Sondell M, Kanje M: Postnatal expression of VEGF and its receptor flk-1 in peripheral ganglia. Neuroreport 2001, 12:105-108

39. Sondell M, Lundborg G, Kanje M: Vascular endothelial growth factor has neurotrophic activity and stimulates axonal outgrowth, enhancing cell survival and Schwann cell proliferation in the peripheral nervous system. J Neurosci 1999, 19: $5731-5740$

40. Sondell M, Sundler F, Kanje M: Vascular endothelial growth factor is a neurotrophic factor which stimulates axonal outgrowth through the flk-1 receptor. Eur J Neurosci 2000, 12:4243-5424

41. Marko SB, Damon DH: VEGF promotes vascular sympathetic innervation. Am J Physiol Heart Circ Physiol 2008, 294: H2646-2652

42. Long JB, Jay SM, Segal SS, Madri JA: VEGF-A and Semaphorin3A: modulators of vascular sympathetic innervation. Dev Biol 2009, 334 : $119-132$

43. Dhondt J, Peeraer E, Verheyen A, Nuydens R, Buysschaert I, Poesen K, Van Geyte K, Beerens M, Shibuya M, Haigh JJ, Meert T, Carmeliet P, Lambrechts D: Neuronal FLT1 receptor and its selective ligand VEGF-B protect against retrograde degeneration of sensory neurons. FASEB J 2011, 25:1461-1473

44. Bellon A, Luchino J, Haigh K, Rougon G, Haigh J, Chauvet S, Mann F: VEGFR2 (KDR/Flk1) signaling mediates axon growth in 
response to semaphorin $3 \mathrm{E}$ in the developing brain. Neuron 2010, 66: 205-219

45. Ruiz de Almodovar C, Fabre PJ, Knevels E, Coulon C, Segura I, Haddick PC, Aerts L, Delattin N, Strasser G, Oh WJ, Lange C, Vinckier S, Haigh J, Fouquet C, Gu C, Alitalo K, Castellani V, Tessier-Lavigne M, Chedotal A, Charron F, Carmeliet P: VEGF mediates commissural axon chemoattraction through its receptor Flk1. Neuron 2011, 70:966-978

46. Erskine L, Reijntjes S, Pratt T, Denti L, Schwarz Q, Vieira JM, Alakakone B, Shewan D, Ruhrberg C: VEGF signaling through neuropiplin 1 guides commissural axon crossing at the optic chiasm. Neuron 2011, 70:951-996 